\title{
Help-seeking by rural residents for mental health problems: the importance of agrarian values
}

\author{
Fiona Judd, Henry Jackson, Angela Komiti, Greg Murray, Caitlin Fraser,
} Aaron Grieve, Rapson Gomez

Objective: To examine the role of stoicism, self-efficacy and perceived stigma in predicting help-seeking by rural residents, for mental health problems.

Method: A cross-sectional community survey was conducted with a sample of 467 rural residents $(58 \%$ female), who completed self-report questionnaires assessing current levels of symptomatology, disability, perceived stigma, self-efficacy, stoicism, attitudes towards and experience of seeking help for psychological problems.

Results: Overall, $27.6 \%(n=129)$ of respondents had sought help from a general practitioner and/or mental health professional for psychological problems or a mental health issue. More women than men reported having sought such help. Lifetime helpseeking for a psychological problem or mental health issue was positively associated with higher levels of distress and lower levels of stoicism and, to a lesser extent, lower levels of self-efficacy.

Conclusions: Efforts to improve help-seeking by rural residents for mental health problems should focus on understanding and addressing attitudes, such as stoicism which act as barriers to help-seeking.

Key words: attitude, help-seeking, mental, rural, stoicism.

\section{Australian and New Zealand Journal of Psychiatry 2006; 40:769-776}

Fiona Judd, Professor (Correspondence); Caitlin Fraser, Research Coordinator

Centre for Rural Mental Health, Monash University School of Psychology, Psychiatry and Psychological Medicine and Bendigo Health Care Group, PO Box 126, Bendigo, Victoria 3552, Australia. Email: fjudd@ bendigohealth.org.au

Henry Jackson, Professor and Head

Department of Psychology, The University of Melbourne, Melbourne, Australia

Angela Komiti, Senior Research Assistant

Department of Psychiatry, The University of Melbourne, Melbourne, Australia

Greg Murray, Senior Lecturer

School of Social and Behavioural Sciences, Swinburne University of Technology, Melbourne, Australia

Aaron Grieve, Postgraduate student; Rapson Gomez, Assistant Professor Department of Psychology, Ballarat University, Ballarat, Australia Received 19 December 2005; accepted 5 January 2006.
Understanding the factors which influence helpseeking is an essential step towards improving the mental health of the community. A variety of models have been developed to systematize research which aims to identify these factors. The Behavioural Model of Health Services Utilization $[1,2]$ proposes that people's use of health services is a function of their predisposition to use services, factors which enable or impede use, and their need for services [2].

Predisposing characteristics, or factors which influence self-recognition of problems and attitudes towards treatment, include: demographics such as gender and age; social structure measured by variables such as education, occupation and ethnicity; and health beliefs. The latter includes attitudes, values and knowledge that people have about health and health services. Enabling resources are the means and knowledge to get into 
treatment and include availability, accessibility and costs of services, as well as awareness of which services exist and what they can provide. Need includes the nature of the illness and its severity.

There are inequalities in the use of mental health services in Australia. Rural residents receive less help from specialist providers than people living in urban areas [3], and it has been shown that the rate of psychological problems managed by general practitioners (GPs) per 1000 population is far lower for rural residents compared with that in metropolitan areas [4]. Available data do not suggest that mental health problems (i.e. need) are less common in rural than in urban areas [5]. Thus, it is likely that the inequity in the use of mental health services is due to less availability or accessibility of services, or the failure to provide services in a culturally appropriate way (less enabling resources), and/or different predisposing factors operating in rural areas.

Self-recognition of mental health problems and the decision to seek treatment have been shown to be influenced by age, gender, marital status, level of education $[3,6,7]$ and a variety of attitudinal factors such as perceived helpfulness of service providers $[8,9]$, perceived stigma associated with mental illness [8-10], as well as mental health literacy [11]. An individual's willingness to seek help for such problems is also likely to be influenced by their willingness to adopt the sick role [12], and their overall attitude towards help-seeking.

Although data are limited, it has been suggested that rural residents are stoic and self-reliant [13], believe that they should cope with their problems and suffer in silence [14], define health as the ability to work or be productive in one's role [15], rely more on family and friends than on health professionals [16], and assume greater self-responsibility for health problems than urban residents [15]. Of note, these studies exploring the attitudes of rural residents towards help-seeking have generally focused on farming communities and/or residents of small and isolated areas. Taken together, these 'agrarian values' may influence both the definition of mental health problems and the probability of help-seeking [10], and thus mitigate against early and effective helpseeking.

Furthermore, it has been suggested that stigma, one of the most potent barriers to help-seeking for mental health problems, maybe a particularly important barrier to mental health care in rural communities [13,16]. Higher levels of perceived stigma have been associated with more negative attitudes towards help-seeking among rural residents [8].This is likely to particularly be a problem in small rural towns where social networks are often closely enmeshed and privacy is lacking [17]. Consistent with this, it has been shown that people living in the towns with a population of less than 2500 were more likely to hold stigmatized attitudes towards mental health care than residents of larger towns, and such attitudes strongly predicted willingness to seek help [10].

While several studies have shown that gender influences help-seeking, the effect of gender may be a more potent factor in rural than in urban residents. Lower rates of help-seeking have been documented for rural compared with urban-dwelling men with mental disorders [18], and rates of suicide are substantially greater in rural compared with that in urban men [19]. The 'agrarian values' described above are regarded by many as descriptors of 'maleness' [20], perhaps accentuated in rural men. Thus, help-seeking for mental health problems by men may be particularly affected by attitudinal factors.

This study aimed to add to existing research by examining the role of a number of attitudinal factors to helpseeking for mental health problems. Specifically, we sought to examine the role of self-efficacy and stoicism (reflecting purported 'agrarian values') and perceived stigma, after controlling for need and sociodemographic variables, and general attitudes towards seeking professional psychological help.

\section{Method}

\section{Sample}

Subjects were recruited from a larger sample of adults $(n=7615)$, recruited randomly from the electoral roll, who had participated in a survey of mental health and wellbeing in rural residents [21]. Subjects in the original study who indicated their willingness to be involved in further research, who lived on farms or in small towns in adjacent geographical locations in Victoria and NSW, identified through having road side mailbox $(\mathrm{RMB})$ addresses $(\mathrm{n}=822)$, were sent a self-report questionnaire containing the measures described below.

\section{Measures}

Sociodemographic details collected in earlier stages of the research included age, sex, marital status, level of education attained and whether a farmer or not.

Current symptomatology was measured using the following scales: the Kessler Psychological Distress Scale (K-10) [22], the Centre for Epidemiological Studies Depression Scale (CES-D) [23] and the state component of the State-Trait Anxiety Scale [24]. Functional disability was measured using the Medical Outcomes Study Short Form (SF-12) [25], a 12-item scale designed to assess limitations or disability experienced over the past 4 weeks because of both physical and mental health difficulties. The SF-12 comprises two subscales: the Mental Component Score (MCS) and the Physical Component Score (PCS).

General attitudes were measured using: 
1. The Liverpool Stoicism Scale (LSS) [26], a 20-item self-report questionnaire that is designed to assess popular views of stoicism, including a lack of emotional involvement, a dislike of free emotional expression and an ability to endure emotion (e.g. 'I do not get emotionally involved when I see suffering on television', 'I tend to keep my feelings to myself', and 'Getting upset over the death of a loved one does not help'). Responses were recorded on a 5-point Likert scale ranging from 'strongly disagree' to 'strongly agree'. Ten items (1, 2, 5, 7, 9, 12, 13, 15, 17 and 18) are reversescored. Higher scores on the LSS reflect greater stoicism.

2. The New General Self-Efficacy Scale (NGSE) [27], an 8-item selfreport questionnaire designed to assess general trait-like selfefficacy, that is, the tendency to view oneself as capable or incapable of meeting demands in a variety of situations (e.g. 'I will be able to achieve most of the goals that I have set for myself'). Responses are recorded on a 5-point Likert scale ranging from 'strongly disagree' to 'strongly agree'. Higher scores reflect greater self-efficacy.

Attitudes towards mental illness and attitudes and experience of treatment were measured using:

1. Perceived Stigma Scale (PSS) [8], a 16-item scale used to assess people's perceptions about the stigma associated with mental illness within their own community (e.g. 'Most people believe that a person who has been treated for a mental illness is dangerous'). The PSS is based on the Devaluation and Discrimination Scale [28], a 12-item scale designed to assess beliefs that most people will devalue or discriminate against people with a mental illness. Responses are recorded on a 4-point Likert scale ranging from 'strongly agree' to 'strongly disagree'. Two items $(6,14)$ are reverse scored. Higher scores reflect more positive attitudes towards mental illness (i.e. less perceived stigma).

2. The Attitudes Towards Seeking Professional Psychological Help Scale (ATSPPH) [29], a 29-item scale to measure general attitudes about seeking professional help for psychological problems (e.g. 'If I believed I was having a mental breakdown, my first inclination would be to get professional help'). Responses are recorded on a 4-point Likert scale ranging from 'strongly agree' to 'strongly disagree'. Eleven items (2, 5, 7, 11, 12, 16, 18, 23, 25, 27, 29) are reverse-scored. Higher scores reflect more positive attitudes towards seeking professional psychological help.

3. The following question was asked to indicate experience of treatment for mental illness: 'Have you ever sought help from a GP and/or mental health professional (i.e. psychiatrist, psychologist, counsellor or mental health services) for a psychological problem or mental health issue?'.

\section{Statistical analysis}

Age was recorded as a continuous measure, sex was coded as male/ female, marital status was coded into three categories: married or living with someone/previously married/single or never married. Level of education was coded into two categories: 12 years or less (of formal education)/13 years or more (of formal education).

Independent samples t-tests were performed to compare men and women on measures of symptoms, distress and attitudinal measures. Significance was set at the 0.01 level to adjust for the multiple com- parisons. Chi-squared analyses was performed to examine whether there were any differences between men and women on help-seeking behaviour for mental health problems.

The data were checked for normality, outliers, reliability of the scales and the assumptions of multicolinearity and homoscedascity. While the attitudinal scales (ATSPPH, NGSE, PSS and LSS) were correlated, the correlations were not high enough to suggest problems with multicolinearity. The symptom and disability measures (CES-D, Speilberger State Anxiety Inventory [STAI] and MCS), however, correlated highly ( $r>0.70$ ) with the K-10 and among themselves, and were therefore excluded from the logistic regression analysis to avoid problems with multicolinearity.

A hierarchical logistic regression analysis was then performed to assess the association between attitudinal measures and help-seeking, after controlling for the influence of need and sociodemographic variables. Specifically, the logistic regression was set up to predict membership in the affirmative response to the item 'Have you ever sought help from a GP and/or mental health professional for a psychological problem or mental health issue?'.

Predictor variables were entered into a hierarchical logistic regression analysis to predict whether help had ever been sought from a GP, psychiatrist, psychologist, counsellor, or mental health services. In the first step, need variables (distress and physical disability scores) were entered, followed by sociodemographic factors (gender, age, education level and marital status) in the second step. Attitudinal variables (stoicism, perceived stigma, attitudes towards seeking professional help, and general self-efficacy) were entered in the third step.

\section{Results}

Questionnaires were returned by 467 individuals, yielding a response rate of 56.8\%. The sample comprised 196 men and 271 women. Respondents were compared with non-respondents on sociodemographic details and a measure of distress (K-10 score) obtained in the previous phase of the research. There were significantly more female respondents than non-respondents and more male non-respondents than respondents. Respondents also had lower K-10 scores than nonrespondents, suggesting that non-respondents had higher distress levels, a finding that is consistent with existing literature However, examination of the differences in scores show that there was only a mean score difference of 1.01 between the two groups. There were no other significant differences between the two groups based on age, education level and marital status (see Table 1).

\section{Current symptoms, disability and help-seeking}

The mean score \pm SD on the K-10 was $15.64 \pm 5.58$. A similar mean score of 14.2 was reported by Andrews and Slade [30], using a normative Australian sample. The mean score \pm SD on the CES-D was $11.09 \pm 8.82$. In a similar study of a small rural Australian community, Wrigley et al. [8] reported a mean \pm SD CES-D score of $11.78 \pm 7.96$.

The mean score \pm SD on the state component of the STAI for the current study was $33.56 \pm 10.84$. Wrigley et al. [8] reported a mean \pm SD STAI score of $32.65 \pm 9.95$ in their study. 
Table 1. Comparing sociodemographic characteristics of respondents and non-respondents

\begin{tabular}{|c|c|c|c|}
\hline & $\begin{array}{l}\text { Respondents } \\
\quad(n=467)\end{array}$ & $\begin{array}{l}\text { Non-respondents } \\
\quad(\mathrm{n}=355)\end{array}$ & $\chi^{2} /$ t-value \\
\hline \multicolumn{4}{|l|}{$\operatorname{Sex}(\%)$} \\
\hline Male & 41.2 & 51.4 & $8.41^{* *}$ \\
\hline Female & 58.8 & 48.6 & \\
\hline Mean age \pm SD (years) & $56.61 \pm 12.89$ & $54.92 \pm 14.81$ & 1.70 \\
\hline \multicolumn{4}{|l|}{ Marital status (\%) } \\
\hline Married/defacto & 82.1 & 83.2 & \\
\hline Previously married & 10.9 & 9.7 & 0.33 \\
\hline Single/never married & 7.1 & 7.1 & \\
\hline \multicolumn{4}{|l|}{ Education level (\%) } \\
\hline 12 years or less & 59.0 & 57.5 & 0.18 \\
\hline 13 years or more & 41.0 & 42.5 & \\
\hline Mean K-10 score \pm SD & $16.30 \pm 5.16$ & $17.31 \pm 6.96$ & $2.18^{*}$ \\
\hline
\end{tabular}

For the current study, the mean scores \pm SD for the MCS and PCS subscales of the SF-12 were $49.48 \pm 10.47$ and $46.30 \pm 10.72$, respectively. Wrigley et al. [8] reported similar results in their study with a mean \pm SD MCS score of $50.75 \pm 8.64$ and a mean \pm SD PCS score of $50.26 \pm 8.12$.

Overall, 27.6\% $(\mathrm{n}=129)$ reported having sought help from a GP and/or mental health professional (i.e. psychiatrist, psychologist, counsellor, or mental health services) for psychological problems or mental health issues.

\section{Attitudes}

Mean \pm SD score on the LSS was $54.71 \pm 9.47$. This compares favourably with the mean \pm SD score of $52.24 \pm 13.22$ reported by Wagstaff and Rowledge [26] in their original study where 62 participants from the community completed the LSS.

The mean \pm SD score on the (transformed) NGSE was $3.02 \pm 0.75$. This compares with means ranging from 3.87 to 4.16 that Chen et al. [27] reported in their original study investigating the validity of the NGSE.

The mean \pm SD PSS score in the current study was $40.10 \pm 4.96$. Wrigley et al. [8] reported a slightly lower mean \pm SD score of $37.51 \pm 4.93$ in their study.

The mean \pm SD ATSPPH score in the current study was $42.98 \pm 7.18$. Wrigley et al. [8] reported a slightly higher mean \pm SD ATSPPH score of $49.88 \pm 8.99$ in their study.

\section{Gender differences on symptom, disability, experience of help-seeking and attitudes}

Gender differences on symptom, disability and attitudinal measures were assessed using independent sample t-tests. Chi-squared analyses were used to investigate potential differences between men and women on help-seeking behaviour.

\begin{tabular}{|c|c|c|c|c|c|}
\hline & \multicolumn{2}{|c|}{ Men } & \multicolumn{2}{|c|}{ Women } & \multirow[t]{2}{*}{$\mathrm{t}$-value } \\
\hline & Mean & SD & Mean & SD & \\
\hline CES-D & 10.67 & 8.33 & 11.67 & 9.37 & 1.16 \\
\hline STAI & 33.73 & 10.40 & 33.60 & 11.41 & 0 \\
\hline $\mathrm{K}-10$ & 15.44 & 5.30 & 15.93 & 5.96 & 0.89 \\
\hline MCS & 50.60 & 9.75 & 48.35 & 11.07 & 2.23 \\
\hline PCS & 45.09 & 11.17 & 46.84 & 10.74 & 1.67 \\
\hline LSS & 59.48 & 7.90 & 51.11 & 8.97 & $10.13 * * *$ \\
\hline NGSE & 31.64 & 4.22 & 31.08 & 4.54 & 1.33 \\
\hline PSS & 39.57 & 4.56 & 40.54 & 5.39 & 1.96 \\
\hline ATSPPH & 41.16 & 6.96 & 44.42 & 7.18 & $4.38 * * *$ \\
\hline \multicolumn{6}{|c|}{$\begin{array}{l}\text { ***p }<0.001 \text {. ATSPPH, Attitudes Towards Seeking Profes- } \\
\text { sional Psychological Help; CES-D, Centre for Epidemiolog- } \\
\text { ical Studies Depression Scale; K-10, Kessler Psychological } \\
\text { Distress Scale; LSS, Liverpool Stoicism Scale; MCS, Mental } \\
\text { Component Score of the SF-12; NGSE, New General Self- } \\
\text { Efficacy Scale; PCS, Physical Component Score of SF-12; } \\
\text { PSS, Perceived Stigma Scale; STAI, Speilberger State } \\
\text { Anxiety Inventory. }\end{array}$} \\
\hline
\end{tabular}

Gender differences in symptom, disability and attitudinal variables are summarized in Table 2.

Men in this sample had higher stoicism scores than women. Wagstaff and Rowledge [26] similarly reported that in their study of community residents, men recorded higher stoicism scores than women. Of interest, the male-female differences reported by Wagstaff and Rowledge [26] were greater than those found in this study (mean \pm SD LSS scores $59.5 \pm 11.3$ vs $45.4 \pm 11.2$ ). Women in this study scored higher than men on the ATSPPH scale, indicating that women had more positive attitudes towards seeking professional psychological help than men. This result is similar to previous findings [e.g. 8]. 
A significantly greater proportion of women $(32.8 \%)$ than men (20.4\%) reported having sought help for a psychological problem in their lifetime $\left(\chi^{2}=8.79, \mathrm{p}<0.01\right)$.

\section{Predicting help-seeking from a GP and/or mental health professional for mental health problems}

At step 1, the model was significant $\chi^{2}(2, \mathrm{n}=350)=48.11$, $\mathrm{p}<0.001$. The K-10 score significantly predicted the dependent variable (odds ratio $[\mathrm{OR}]=1.17$, confidence interval $[\mathrm{CI}]=1.11-1.23$, $\mathrm{p}<0.001$ ), with higher distress scores associated with a greater likelihood of having sought help.

The addition of the sociodemographic variables at step 2 made a significant contribution to the model, the block model was significant $\chi^{2}(5, \mathrm{n}=350)=14.57, \mathrm{p}<0.05$. Gender was the only sociodemographic variable that was a significant predictor of the dependent variable $(\mathrm{OR}=2.39, \mathrm{CI}=1.36-4.22, \mathrm{p}<0.01)$. Compared with men, women were twice as likely to have ever sought help for psychological problems. The K-10 remained a significant predictor of the dependent variable $(\mathrm{OR}=1.16, \mathrm{CI}=1.11-1.23, \mathrm{p}<0.001)$.

The addition of the attitudinal variables in the final step made a significant contribution to the overall model, the block model was significant $\chi^{2}(4, \mathrm{n}=350)=20.60, \mathrm{p}<0.001$. Stoicism (LSS) and general self-efficacy (NGSE) were the only attitudinal variables that were independent predictors of the dependent variable. Lower stoicism and lower self-efficacy scores were associated with a greater likelihood of having sought professional help. There was also a trend for more positive attitudes towards seeking help (ATSPPH) as a predictor of the help-seeking. Distress (K-10 score) remained an independent predictor of the independent variable. However, the effect of gender was rendered non-significant after the addition of the attitudinal variables. To clarify whether there was an interaction effect between gender and stoicism, an interaction term sex X stoicism was added to the model in a fourth step. The interaction term was not a significant predictor of helpseeking, suggesting that the effects of gender and stoicism were main effects only. However, addition of the interaction term rendered the effect of stoicism score non-significant, although a trend remained $(\mathrm{OR}=0.94, \mathrm{CI}=0.88-1.00, \mathrm{p}=0.053)$.

The final model was significant $\chi^{2}(12, \mathrm{n}=350)=83.35, \mathrm{p}<0.001$. Results of the logistic regression model at each of the four steps are presented in Table 3.

\section{Discussion}

The sample for the current study was purposely selected from rural inland regions in Victoria and New South Wales. Rather than studying a heterogeneous rural sample, which may include a range of locales such as rural towns of various sizes, major regional centres, large coastal regions and peri-urban communities, these areas were selected in order to generate a sample of respondents that were representative of small rural towns and adjacent farming environs. The study focused on these locales, as it is residents in these areas that have been previously described in the literature as possessing the 'agrarian values' of interest in this study.

The focus of this paper was assessing the role of attitudes in predicting help-seeking for psychological problems from a GP and/or mental health professional among rural residents. Almost a third of respondents indicated that they had previously sought professional help for a mental health problem. Consistent with previous research, need (i.e. self-reported symptoms) did influence actual help-seeking with higher distress scores associated with greater likelihood of having sought help.

Consistent with our expectations, more women than men reported help-seeking. Women had more positive attitudes towards seeking professional help for psychological problems, and scored lower on the measure of stoicism. A gender difference in levels of stoicism has been noted previously. Of interest, the gender difference demonstrated here was less than that previously found in a heterogenous community sample in Britain, perhaps suggesting that the attitudes of rural women vary from those of female residents in other locales.

Contrary to expectations, perceived stigma did not influence lifetime help-seeking, nor did reported attitudes towards seeking professional help for psychological problems. The reasons for this are unclear, but one possible explanation is the organization of health services in small rural towns. Given the lack of availability of specialist mental health services in these areas, it is likely that most people who sought help did so from a GP or at a local community mental health service. Seeking help from these 'local' services and providers may be associated with less stigma than attending a specialist mental health service or provider. Second, there has been significant community education, political activism and advocacy directed towards reducing the stigma associated with mental illness. The findings relating to stigma and attitudes towards seeking help may reflect the effects of these activities. Despite the clear gender differences described above, sex did not remain an independent predictor of help-seeking after the addition of the attitudinal variables. There were no effects of marital status and education on help-seeking. The effects of marital status and education have not been as consistent as the gender effect reported in the literature. Higher levels of stoicism were associated with less likelihood of having sought help for mental health problems. There did not appear to be an interaction effect between sex and stoicism, suggesting that stoicism had a main effect on help-seeking. A higher level of general self-efficacy was also associated with less likelihood of having sought help.

Denial, suppression and control of emotions are regarded as key features of the modern concept of stoicism [26] and are expressed as lack of emotional 
Table 3. Summary of the logistic regression analysis predicting lifetime help-seeking from a GP and/or mental health professionals for psychological problems

\begin{tabular}{|c|c|c|c|c|}
\hline Predictor & B & SE & Wald statistic & OR $(95 \% \mathrm{Cl})$ \\
\hline \multicolumn{5}{|l|}{ Step 1} \\
\hline PCS & 0.02 & 0.01 & 3.69 & $1.02(1.00-1.05)$ \\
\hline $\mathrm{K}-10$ & 0.16 & 0.03 & 39.46 & $1.17(1.11-1.23) * * *$ \\
\hline \multicolumn{5}{|l|}{ Step 2} \\
\hline PCS & 0.01 & 0.01 & 0.89 & $1.01(0.99-1.04)$ \\
\hline $\mathrm{K}-10$ & 0.15 & 0.03 & 32.40 & $1.16(1.10-1.22) * * *$ \\
\hline Sex - female & 0.87 & 0.29 & 9.11 & $2.39(1.36-4.22) * *$ \\
\hline Age & -0.02 & 0.01 & 2.42 & $0.98(0.96-1.01)$ \\
\hline Education -13 years or more & -0.25 & 0.28 & 0.80 & $0.78(0.45-1.35)$ \\
\hline Previously married $\dagger$ & 0.37 & 0.45 & 0.66 & $1.45(0.59-3.52)$ \\
\hline Single/never married $\dagger$ & -0.44 & 0.58 & 0.58 & $0.65(0.21-2.00)$ \\
\hline \multicolumn{5}{|l|}{ Step 3} \\
\hline PCS & 0.02 & 0.01 & 1.88 & $1.02(0.99-1.05)$ \\
\hline $\mathrm{K}-10$ & 0.13 & 0.03 & 19.47 & $1.14(1.08-1.21)^{* * *}$ \\
\hline Sex - female & 0.25 & 0.33 & 0.57 & $1.28(0.67-2.44)$ \\
\hline Age & -0.01 & 0.01 & 0.73 & $0.99(0.96-1.02)$ \\
\hline Education - 13 years or more & -0.21 & 0.29 & 0.50 & $0.81(0.46-1.45)$ \\
\hline Previously married $\dagger$ & 0.47 & 0.48 & 0.96 & $1.60(0.63-4.07)$ \\
\hline Single/never married $\dagger$ & -0.33 & 0.59 & 0.32 & $0.72(0.22-2.29)$ \\
\hline LSS & -0.06 & 0.02 & 9.26 & $0.94(0.91-0.98)^{* *}$ \\
\hline PSS & -0.02 & 0.03 & 0.27 & $0.99(0.93-1.04)$ \\
\hline ATSPPH & 0.03 & 0.02 & 1.99 & $1.03(0.99-1.08)$ \\
\hline NGSE & -0.08 & 0.04 & 4.76 & $0.92(0.86-0.99) *$ \\
\hline \multicolumn{5}{|l|}{ Step 4} \\
\hline PCS & 0.02 & 0.01 & 1.80 & $1.02(0.99-1.05)$ \\
\hline $\mathrm{K}-10$ & 0.13 & 0.03 & 19.43 & $1.14(1.08-1.21)^{* * * *}$ \\
\hline Sex - female & -0.33 & 2.12 & 0.23 & $0.72(0.01-46.41)$ \\
\hline Age & -0.01 & 0.01 & 0.72 & $0.99(0.96-1.02)$ \\
\hline Education - 13 years or more & -0.21 & 0.29 & 0.49 & $0.81(0.46-1.45)$ \\
\hline Previously married $\dagger$ & 0.47 & 0.48 & 0.96 & $1.60(0.63-4.07)$ \\
\hline Single/never married $\dagger$ & -0.35 & 0.60 & 0.34 & $0.71(0.22-2.28)$ \\
\hline LSS & -0.06 & 0.03 & 3.74 & $0.94(0.88-1.00)$ \\
\hline PSS & -0.02 & 0.03 & 0.26 & $0.99(0.93-1.04)$ \\
\hline ATSPPH & 0.03 & 0.02 & 1.98 & $1.03(0.99-1.08)$ \\
\hline NGSE & -0.08 & 0.04 & 4.65 & $0.92(0.86-0.99) *$ \\
\hline Sex X LSS & 0.01 & 0.04 & 0.07 & $1.01(0.94-1.09)$ \\
\hline
\end{tabular}

involvement, lack of emotional control and the exercising of emotional control [26]. Stoicism defined in this way captures many aspects of attitudes and behaviours documented in rural residents [13]. High levels of stoicism may influence help-seeking for mental health problems in two important ways. First, individuals with such attitudes may report fewer mental health symptoms simply because they do not define such problems as illness. If this is the case, rural residents are likely to delay seeking help until symptoms are severe and disabling. This is consistent with the 'rural definition' of health as ability to work or be productive in one's role [15]. Alternatively, they may simply be reticent to admit that they have an illness or that they need treatment [10].

Self-efficacy, also found to be a predictor of helpseeking behaviour, is a second key component of frequently described 'agrarian values'. Of note, unlike stoicism, levels of self-efficacy as measured by NGSE scale scores were not different for men and women. Our finding that higher levels of self-efficacy were associated with less likelihood of having sought help is consistent with previous studies noting rural residents assume greater self-responsibility for health problems than urban residents. 
To date, efforts to improve help-seeking for mental health problems have largely focused on improving mental health literacy of the community [11] and reducing the stigma associated with experiencing and seeking treatment for a mental illness (e.g. [31]). The findings here suggest that while these are important, at least in some groups, these may not be sufficient areas for attention. For example, while stoic individuals tend not to define problems as illnesses, they also may actively seek to avoid situations where they will be encouraged to talk about their problems, thoughts and emotions. For such individuals, in addition to improving mental health literacy, mental health services may also need to be framed/ described in such a way as to alleviate any concerns about admitting and dealing with emotions and problems.

There are important limitations with this study. First, the respondents are a selected group. They previously participated in a mail-out survey and agreed to ongoing involvement in the research. A comparison of respondents with non-respondents in the study found that nonrespondents were more likely to be male and to have slightly higher distress levels. Also, because participants were deliberately selected on the basis of having RMB addresses, the results in this study can only be applied to small rural towns and adjacent farming environs. A second important limitation is that the mean age of participants was 56 years, so younger residents are underrepresented. Third, we used current distress levels to predict lifetime help-seeking. Finally, respondents retrospectively reported lifetime help-seeking behaviours.

The findings of this study suggest that general attitudinal factors are important determinants of help-seeking behaviour. The factors examined here, self-efficacy, stoicism and perceived stigma were chosen as they seemed particularly relevant to rural residents. Stoicism has been widely written about in popular literature as well as health literature relating to rural residents, but has been neglected as a focus of systematic research. The findings here suggest that this deficit needs to be redressed.

Stoic attitudes together with high levels of self-efficacy may not only mitigate against help-seeking, but also make it difficult for health providers to detect problems when an individual actually does present seeking help. Further research is needed to explore more fully the concept of stoicism, to determine how best to measure this, to examine how it interacts with other important attitudinal variables such as self-efficacy, to investigate whether the effects are unique to or particularly important in rural residents, and to develop means to enable those who are stoic to seek help when experiencing difficulties.

\section{Acknowledgement}

This study was in part supported by a grant from beyondblue, The National Depression Initiative.

\section{References}

1. Andersen RA, Newman JF. Societal and individual determinants of medical care utilization in the United States. Milbank Quarterly 1973; 51:95-124.

2. Andersen RA. Revisiting the behavioral model and access to medical care. Does it matter? Journal of Health and Social Behavior 1995; 36:1-12.

3. Paslow RA, Jorm AF. Who uses mental health services in Australia? An analysis of data from the National Survey of Mental Health and Wellbeing. Australian and New Zealand Journal of Psychiatry 2000; 34:997-1008.

4. Caldwell TM, Jorm AF, Knox S, Braddock D, Dear KB, Britt H. General practice encounters for psychological problems in rural, remote and metropolitan areas in Australia. Australian and New Zealand Journal of Psychiatry 2004; 38:774-780.

5. Australian Bureau of Statistics. Mental health and wellbeing: profile of adults, Australia. Canberra: Australian Bureau of Statistics, 1997.

6. Lin E, Goering P, Offord DR, Campbell D, Boyle MH. The use of mental health services in Ontario: epidemiologic findings. Canadian Journal of Psychiatry - Revue Canadienne de Psychiatrie 1996; 41:572-577.

7. Leaf PJ, Bruce ML. Gender differences in the use of mental health-related services: a re-examination. Journal of Health and Social Behavior 1987; 28:171-183.

8. Wrigley S, Jackson H, Judd F, Komiti A. The role of stigma and attitudes towards help-seeking from a GP for mental health problems in a rural town. Australian and New Zealand Journal of Psychiatry 2005; 39:514-521.

9. Humphreys JS, Mathews-Cowey S, Weinand HC. Factors in accessibility of general practice in rural Australia. Medical Journal of Australia 1997; 166:577-580.

10. Hoyt DR, Conger RD, Valde JG, Weihs K. Psychological distress and help seeking in rural America. American Journal of Community Psychology 1997; 25:449-470.

11. Jorm AF, Korten AE, Jacomb PA, Christensen H, Rodgers B, Pollitt P. 'Mental health literacy': a survey of the public's ability to recognise mental disorders and their beliefs about the effectiveness of treatment. Medical Journal of Australia 1997; 166:182-186.

12. Bucholz KK, Robins LN. Who talks to a doctor about existing depressive illness? Journal of Affective Disorders 1987; 12:241250.

13. Fuller J, Edwards J, Procter N, Moss J. How definition of mental health problems can influence help seeking in rural and remote communities. Australian Journal of Rural Health 2000; 8:148153.

14. Ide M. Caring for the health of isolated women. In: Women's Health in a Changing Society: National Women's Health Conference Proceedings. Adelaide, SA, 1986.

15. Weinert $\mathrm{C}$, Long K. Understanding the health care needs of rural families. Family Relations 1987; 36:450-455.

16. Fox JC, Blank M, Rovnyak VG, Barnett RY. Barriers to help seeking for mental disorders in a rural impoverished population. Community Mental Health Journal 2001; 37:421436.

17. Rost K, Smith R, Taylor JL. Rural-urban differences in stigma and the use of care for depressive disorders. Journal of Rural Health 1993; 9:57-62. 
18. Caldwell TM, Jorm AF, Dear KB. Suicide and mental health in rural, remote and metropolitan areas in Australia. Medical Journal of Australia 2004; 181 (Suppl 7):S10-S14.

19. Australian Bureau of Statistics. Suicides: recent trends. Canberra: Australian Bureau of Statistics, 2000.

20. Courtenay WH. Constructions of masculinity and their influence on men's well-being: a theory of gender and health. Social Science and Medicine 2000; 50:1385-1401.

21. Murray G, Judd F, Jackson H et al. Rurality and mental health: the role of accessibility. Australian and New Zealand Journal of Psychiatry 2004; 38:629-634.

22. Kessler RC, Andrews G, Colpe LJ et al. Short screening scales to monitor population prevalences and trends in non-specific psychological distress. Psychological Medicine 2002; 32:959976.

23. Radloff LS. The CES-D scale: a self-report depression scale for research in the general population. Applied Psychological Measurement 1977; 1:385-401.

24. Spielberger CD, Gorsuch RL, Lushene RE. Manual for the StateTrait Anxiety Inventory. Palo Alto, CA: Consulting Psychologists, 1983.
25. Ware JE, Kosinski M, Keller SD. A 12-item short form health survey. Medical Care 1996; 34:220-233.

26. Wagstaff GF, Rowledge AM. Stoicism: it's relation to gender, attitudes towards poverty, and reactions to emotive material. The Journal of Social Psychology 1995; 135:181-184.

27. Chen G, Gully SM, Eden D. Validation of a new general selfefficacy scale. Organizational Research Methods 2001; 4:6283.

28. Link BG. Understanding labeling effects in the area of mental disorders: an assessment of the effects of expectations of rejection. American Sociological Review 1987; 52:96-112.

29. Fisher EH, Turner JL. Orientations to seeking professional help: development and research utility on an attitude scale. Journal of Consulting and Clinical Psychology 1970; 35:79-90.

30. Andrews G, Slade T. Interpreting scores on the Kessler Psychological Stress Scale (K10). Australian and New Zealand Journal of Public Health 2001; 25:494-497.

31. Vaughan G, Hansen C. 'Like Minds, Like Mine': a New Zealand project to counter the stigma and discrimination associated with mental illness. Australasian Psychiatry 2004; 12:113-117. 